\title{
Controlling pH in a Precipitation Process
}

\author{
KJELL STØLE-HANSEN ${ }^{1}$ and BJARNE A. FOSS
}

Keywords: $p H$ control, metals, chemical industry, dynamic models

\begin{abstract}
This paper deals with $\mathrm{pH}$ control in a precipitation and dissolution process. The process is a part of the electrolyte purification plant at Falconbridge Nikkelverk in Kristiansand, Norway. The process including the present strategy for $\mathrm{pH}$ control are presented, and experienced weaknesses with this strategy are described. A rigorous dynamic model of the process is briefly summarized. This model was developed in earlier work with the purpose of being a tool for control design. Because of the precipitation in form of hydroxides and the limited dissolution of nickel carbonate, the process is approximately linear in $\mathrm{pH}$. Therefore, an alternative strategy for $\mathrm{pH}$ control based on adding derivative and feed forward action is suggested. The alternative control strategy is by simulations shown to give severe improvements in performance. The stability of the proposed controller is briefly analysed.
\end{abstract}

\section{Introduction}

At Falconbridge Nikkelverk in Kristiansand, Norway, nickel is produced by an aqueous electrowinning process. Before the electrowinning the nickel solution is processed in an electrolyte purification plant, where impurities like lead and manganese are removed by chemical precipitation. The preciptitation process takes place in a column reactor (plug like flow), and is controlled by addition of chlorine gas as an oxidating agent, followed by nickel carbonate to increase the $\mathrm{pH}$ value to the desired level, thereby reducing the solubility of the impurities, which precipitate as oxides and hydroxides. The present strategy for $\mathrm{pH}$ control, based on a single PI-controller, sometimes introduce oscillations in the $\mathrm{pH}$ value and hence performs inadequately. Today, the use of chemicals (i.e. chlorine gas and nickel carbonate), dominates the operational costs in this section. This is the background and motivation for renewing the control design.

The scope of the present work is to design an improved strategy for $\mathrm{pH}$ control for the precipitation process.

In a previous paper (Støle-Hansen and Dotterud 1996), a rigorous model of the precipitation reactor was developed. This model was validated by using steady state reactor profiles of composition and $\mathrm{pH}$, and time series of the effluent $\mathrm{pH}$ value. $\mathrm{A}$ resumé of the model development is given in the Appendix.

Control of $\mathrm{pH}$ has generally received a lot of attention in the literature, and Gustafsson and Waller (1992) gives a short survey of some of the studies. The achieved popularity is probably due to the inherent nonlinear characteristics of $\mathrm{pH}$ processes, the available and simple mathematical models and the low experimental costs, which all

\footnotetext{
'To whom correspondence should be addressed. Phone: + 477359 4376. E-mail: ksh@itk. ntnu.no. Fax: + 477359 4399. WWW: http://www.itk.ntnu.no/ansatte/Stoele-Hansen_Kjell.

Received 23 May 1997.

This paper was presented at the IFAC Symposium on Advanced Control of Chemical Processes (ADCHEM-97), Banff, Canada, June 1997. It is reprinted with permission from Elsevier Science Ltd.
} 
make this type of process attractive candidates for testing new control algorithms. Precipitation processes in $\mathrm{pH}$ systems, though, has not been treated to the same extent, even if they are quite frequent in chemical process industry (e.g. purification processes and waste-water treatment). Some recent contributions treating modelling and control of precipitation processes are given by Sandström and Gustafsson (1994), Wright and Kravaris (1995), Holcroft et al. (1995) and Gustafsson et al. (1995).

The outline of this paper is as follows. First we give a brief process description. Further, we demonstrate the weaknesses of the present control strategy by simulations, analyse the dynamics of the process and thereby design an alternative control strategy. Then the new and present control algorithms are compared, the stability of the new controller is briefly analysed and we finish the paper with a conclusion.

\section{Process Description}

A sketch of the vertical precipitation reactor is shown in Fig. 1. The main feed stream enters the reactor at the top through a static mixer, which is partly submerged into the solution. The flow is directed downwards to the bottom of the reactor, and turns up again on the other side of the vertical partition wall. The effiuent stream leaves the reactor by an overflow mechanism. The flow rate of chlorine gas, introduced in front of the static mixer, is manually controlled by the operators based on on-line sampling and analysis of filtrate impurity content. Chlorine gas is added in some excess versus stoichiometric requirements according to the subsequent hydrolysis reactions of oxidized metal cations.

$\mathrm{NiCO}_{3}$, introduced as a slurry in a separate pipe some distance below the static mixer, dissolves and increases $\mathrm{pH}$ in the solution. The $\mathrm{NiCO}_{3}$ flow rate is controlled by a PI-controller reading the $\mathrm{pH}$-value in the effluent stream. At increased $\mathrm{pH}$, oxidized base metal cations like $\mathrm{Pb}(\mathrm{IV})$ and $\mathrm{Ni}(\mathrm{III})$ will hydrolyse and precipitate as oxides and hydroxides. The precipitates are removed in a subsequent filter. The hydrolysis produce free acid, which is consumed by the carbonate, thus buffering the system to keep the $\mathrm{pH}$ fairly steady in the reacting zone of the vertical reactor. The parallel and consecutive reaction scheme for $\mathrm{Ni}$ and $\mathrm{Pb}$ taking place are shown below (Table 1).

Other minor impurities co-precipitating in the reactor are $\mathrm{Mn}, \mathrm{Co}$ and $\mathrm{Fe}$. These compounds, not considered in this paper, react in a similar manner as $\mathrm{Pb}$ and $\mathrm{Ni}$. Other

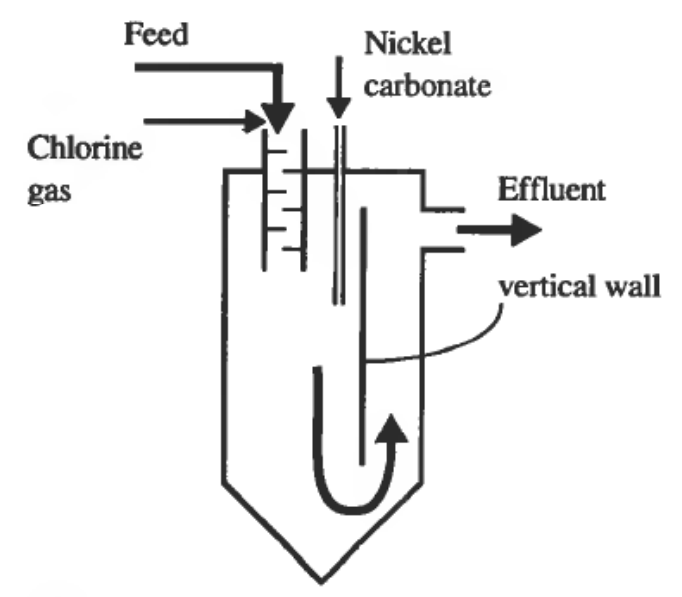

Figure 1. A sketch of the precipitation reactor. 


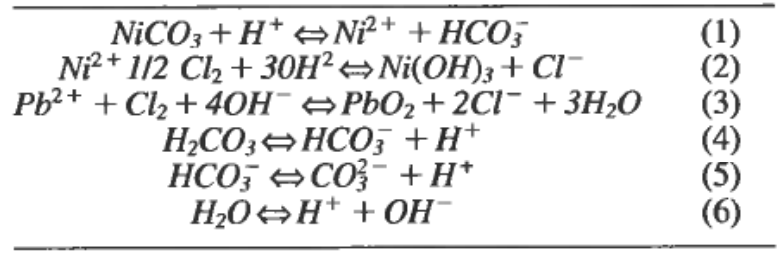

Table 1. Main reactions.

constituents not involved in the chemical reactions are sodium and sulphate. Formation of complexes is not considered in this work.

\section{Process Analysis and Present Control Strategy}

A dynamic nonlinear model developed for this process is described in the Appendix (Støle-Hansen and Dotterud 1996). Based on the results from this work we can draw a schematic view of the reactor and the present control configuration as given in Fig. 2 (the feed forward loop is not a part of the present control strategy, see next section). The $\mathrm{pH}$ controller is a standard PI-controller (Proportional + Integral) and reads the effluent $\mathrm{pH}$ value. Throughout this work we will use a set point value of 4.2. Further we assume that the $\mathrm{pH}$-electrode have internal dynamics (Hershkovitch et al. 1978), and therefore add a first order dynamic element (time constant $=5 \mathrm{~s}$, which is fairly short for an industrial probe) between the $\mathrm{pH}$-electrode and the controller. $\mathrm{pH}$-probes often show an asymmetric behaviour during transient periods, but this phenomena is not considered in this work. We also assume that the actuator (control valve) for the feed of nickel carbonate has the same type of internal dynamic as well (time constant $=5 \mathrm{~s}$ ).

The main challenge for the $\mathrm{pH}$ controller are variations in composition in the feed (FNA 1994-97). It is also assumed that the addition of chlorine gas will not directly influence pH value in the reactor (Støle-Hansen and Dotterud 1996). We will therefore treat this $\mathrm{pH}$ control problem as a SISO problem. Hence we assume that sufficiently amounts of chlorine gas has been added to the process, and that the precipitation processes are not limited due to lack of the oxidizing agent. In the simulations performed in this work we will use the simulator setup shown in Fig. 2, where each CSTR-unit represents a dynamic nonlinear model.

The $\mathrm{pH}$ value in the feed will follow a periodic step function varying between 2.5

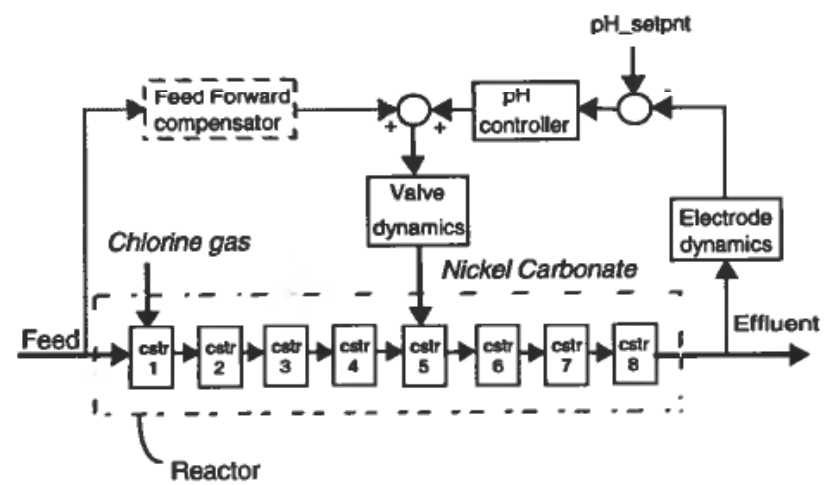

Figure 2. Principal view of the reactor and control configuration. 

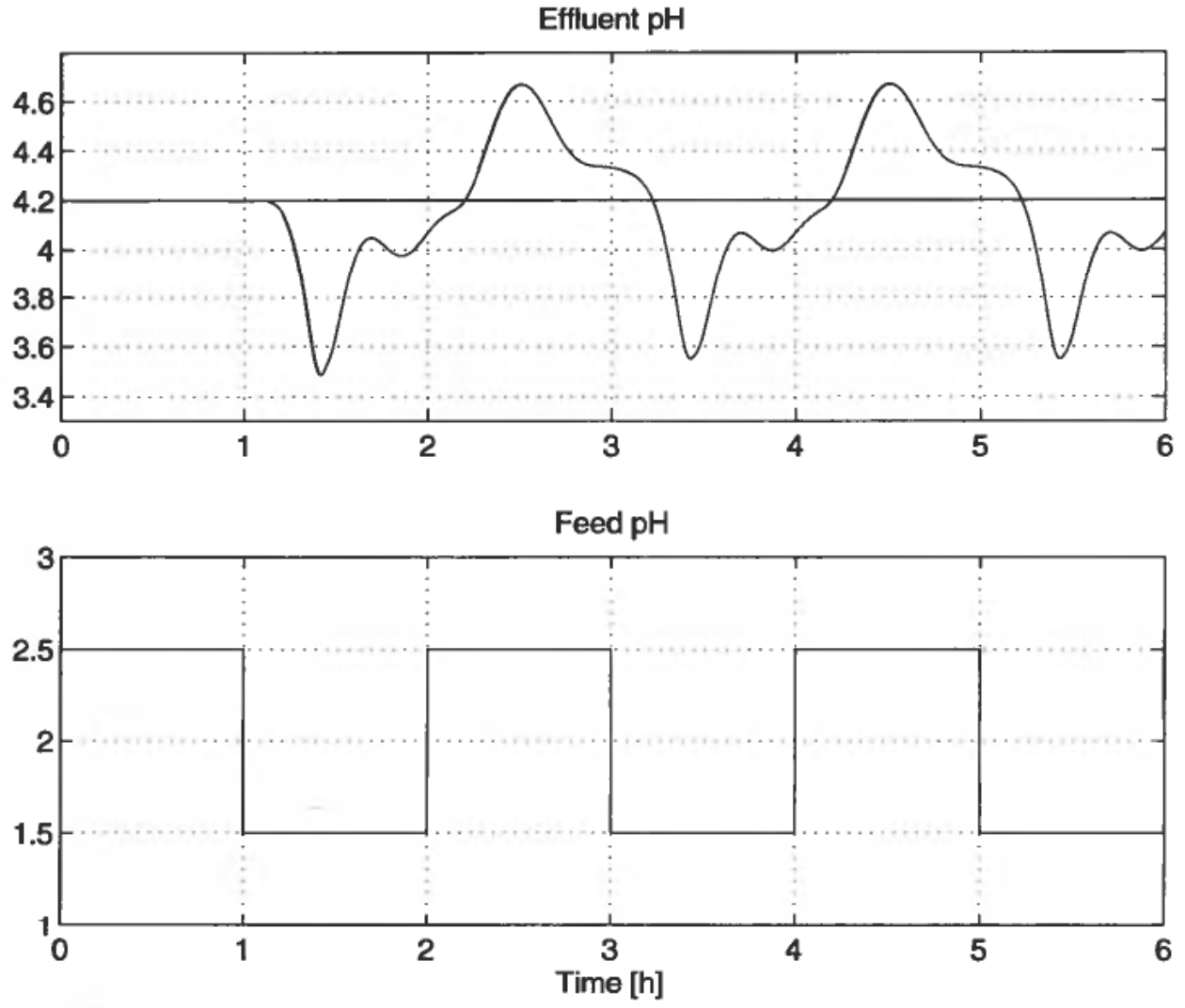

Figure 3. Input $\mathrm{pH}$ disturbance in feed and performance of present $\mathrm{pH}$ controller (PI).

to 1.5 with a period of 2 hours. We will use this input disturbance throughout this work. The flow of chlorine gas is kept constant during the simulations.

The disturbance in input $\mathrm{pH}$ and the respective simulated effluent $\mathrm{pH}$ and actuation value are shown in Fig. 3 for the present control strategy. The PI controller was tuned by the standard Ziegler-Nichols procedure $(\mathrm{Kp}=1 \cdot 1, \mathrm{Ti}=800 \mathrm{~s})$. The given disturbance in the feed stream causes deviations from the set point up to 0.7 in the effluent $\mathrm{pH}$ value.

\section{Design of an Alternative Control Strategy}

$\mathrm{pH}$ processes are, as discussed in the introduction, in general highly nonlinear. The complexity of these type of systems are sometimes increased due to phenomena like buffering and precipitation (Gustafsson et al. 1995). Variations in the composition of the feed may change the buffering capacity and hence the dynamics in the system. As a part of the process analysis, we have plotted the steady state titration curve (effluent $\mathrm{pH}$ value as a function of input nickel carbonate) for the precipitation process in Fig. 4. The curve is calculated by using the nonlinear dynamic model (Støle-Hansen and Dotterud 1996). Note that even if the process is in steady state when the titration curve is recorded, the precipitation and dissolution reactions will not necessarily be in equilibrium (because a continuous-flow reactor is used). The figure shows that the process is approximately linear in $\mathrm{pH}$ in the operational area $(\mathrm{pH}=4 \cdot 1-4 \cdot 5)$. This observation is somewhat surprising. The reason for the linear behaviour is that when 


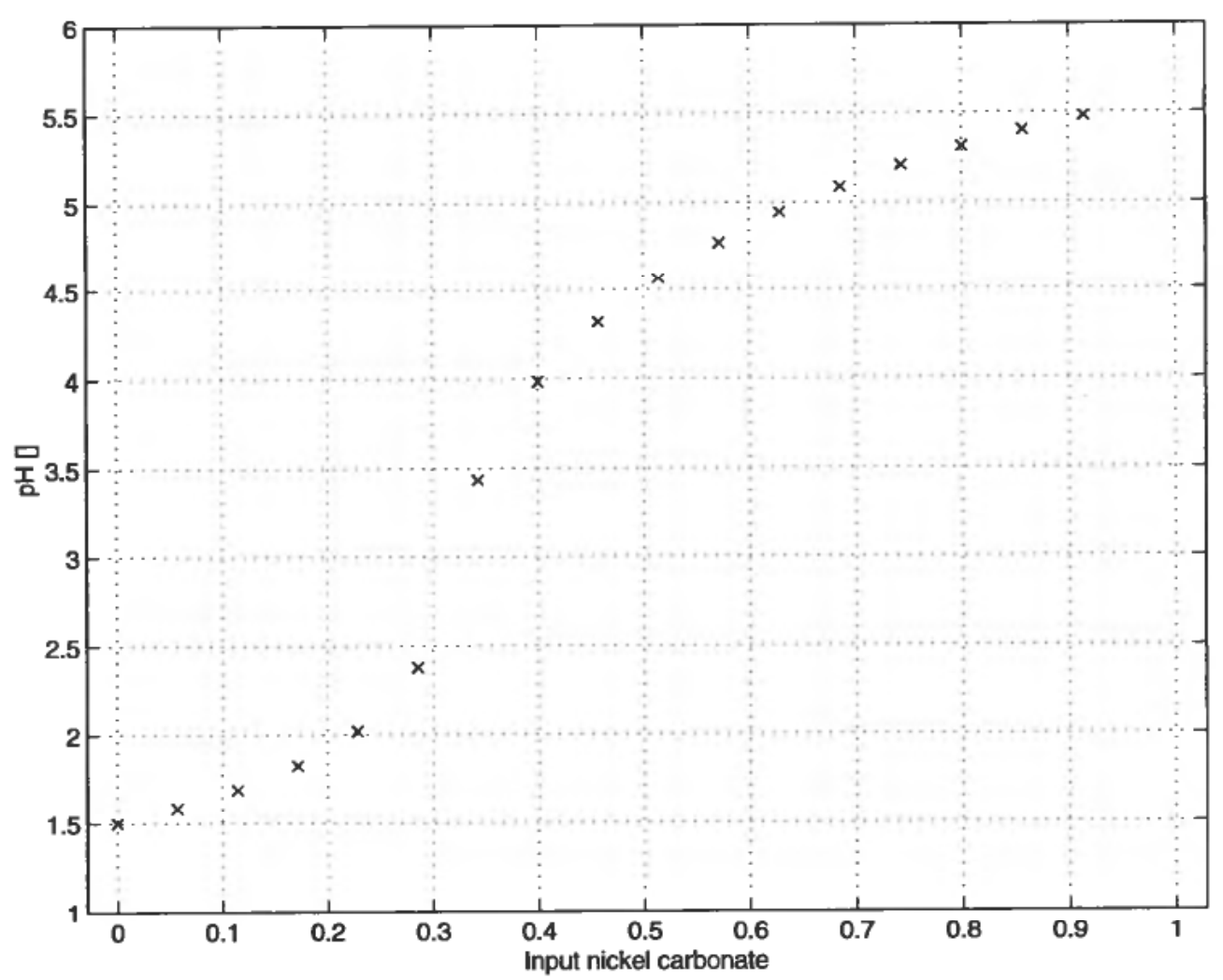

Figure 4. The calculated titration curve for the precipitation reactor ( $\mathrm{x}$-axis made anonymous).

the $\mathrm{pH}$ increase due to addition of nickel carbonate, the rate of precipitation also increases. The precipitation process produces acid (see Table 1), and hence counteracts the effect of adding a strong base to the system. That is the main reason why the $\mathrm{pH}$ does not increase more rapidly. Another reason for that the titration curve seems to 'flatten out' is that the dissolution rate of nickel carbonate is limited (specially with high $\mathrm{pH}$ values), and hence not all of the carbonate will be effective when adding large quanta.

We can now approximate the behaviour of the process from the carbonate input to the effluent with a $4^{\text {th }}$ order transfer function. This observation is very important, because it indicates that we can limit the set of potential new controllers to linear controllers. Hence, we improve controller performance by increasing the order of the original PI-controller by adding derivative action (Waller and Gustafsson 1986). In Fig. 5 we have plotted the output $\mathrm{pH}$ and the actuator value using a PID controller, and otherwise the same input conditions as in Fig. 3. The PI-controller performance is plotted for comparison. The PID controller is also tuned by the Ziegler-Nichols procedure $(\mathrm{Kp}=1.6, \mathrm{Ti}=500 \mathrm{~s}, \mathrm{Td}=200 \mathrm{~s})$. The performance is radically improved by introducing derivative action, and the deviations from the set point are reduced to 0.2 in magnitude compared to 0.7 for the PI-controller case.

\section{Stability}

Since the process is approximately linear, we can use classical linear methods to analyse the controllers stability and tuning parameters. The slope of the curve in Fig. 4 represents the gain in an approximated linear model. The gain can be estimated to 

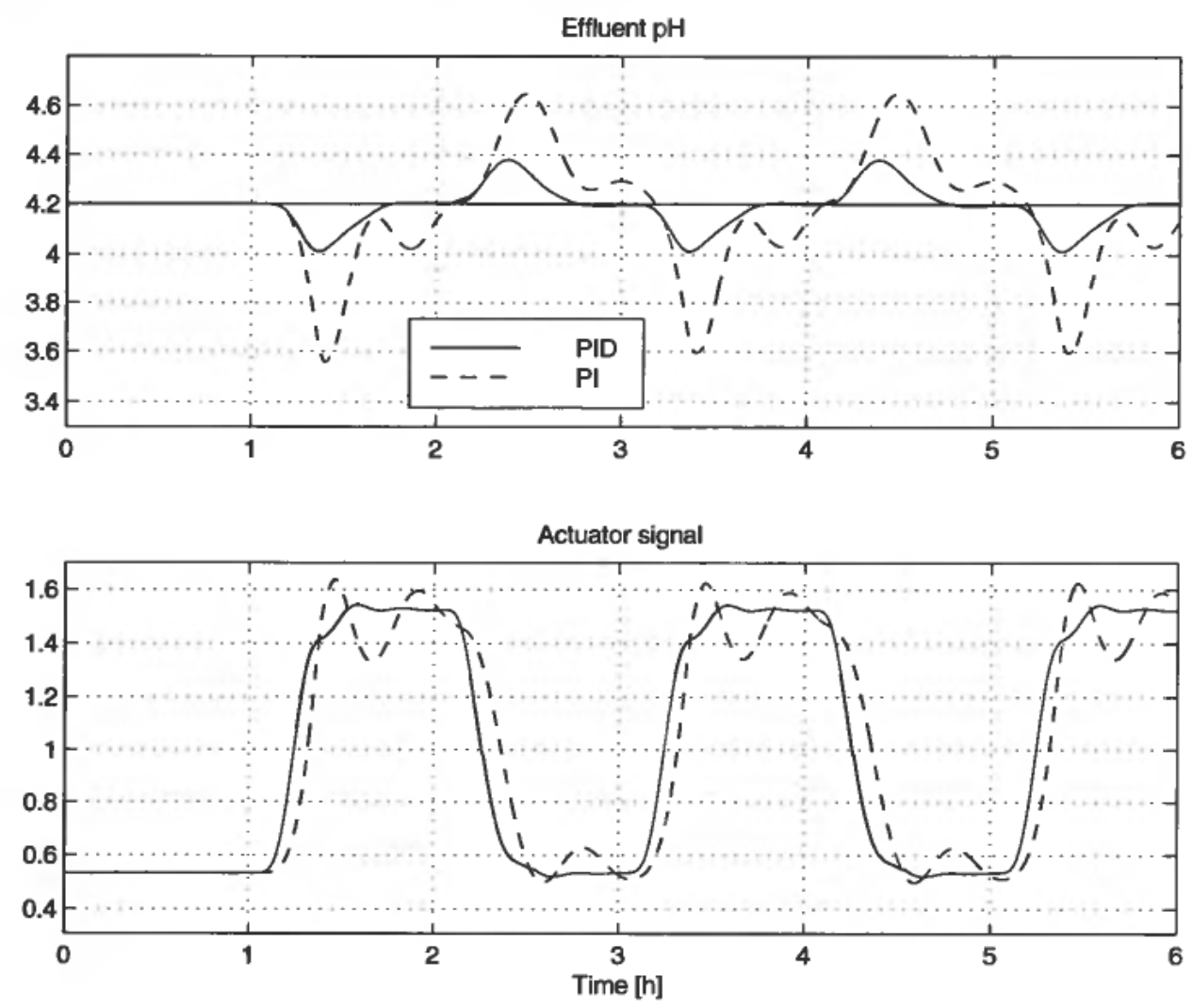

Figure 5. PID and PI controller performance.

\begin{tabular}{lccccc}
\hline & P & I [s] & D [s] & Gm [dB] & Pm [deg] \\
\hline PI & $1 \cdot 1$ & 800 & 0 & 4 & 25 \\
PID & $1 \cdot 5$ & 600 & 200 & 4 & 20 \\
\hline
\end{tabular}

Table 2. Stability margins.

be: $G p=1.4$ at $\mathrm{pH}$ values around 4.2. If we use this approximated linear model and the parameters of the PI and PID controllers we can compute the phase and gain margins for the two control loops using a bode-plot. The results are summarized in Table 2. This table shows acceptable stability margins, though less than standard margins given in text books $(P m=\sim 30-45 \mathrm{deg}, \mathrm{Gm}=\sim 6 \mathrm{~dB})$. By reducing the gain, the controllers can be made less aggressive. The table shows, however, that the stability margins for the PI and the PID controller are almost equal.

\section{Feed Forward Compensation}

A common and often necessary way to further improve an industrial control system is by introducing a feed forward part (Slotine and $\mathrm{Li} \mathrm{1991).} \mathrm{As} \mathrm{the} \mathrm{main} \mathrm{disturbances}$ are fluctuations in $\mathrm{pH}$ in the feed stream (see Fig. 2), this seems to be a promising strategy in this case. In practice are two forms of feed forward compensators used (Newell and Lee 1988): 


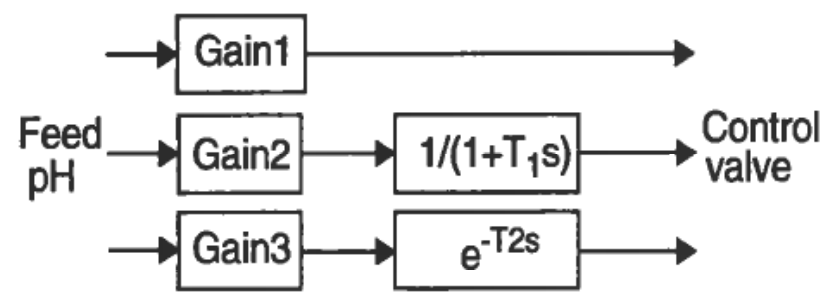

Figure 6. The different feed forward structures (one static and two dynamic).

1. Static single gain

2. Dynamic compensation

The feed forward design is a trade-off between performance and robustness, where a dynamic compensator in theory may perfectly compensate disturbances. This is true as long as the model is an accurate representation of the process.

We designed two types of feed forward compensators, where one is a fixed gain compensator (static), and the second is a fixed gain compensator transferred through a dynamic element, see Fig. 6 . This fixed gain is in practice a tuning parameter, where full compensation means putting it equal to the theoretically correct value. In this work a value of half the theoretical value gave the best result. Ideally the dynamic elements should consist of four first order transfer functions (see Fig. 2), because there are four CSTR-elements from the feed inlet to where the nickel carbonate enters the reactor. But in the light of the robustness comments above, however, we use only one first order transfer in the simulation, or a pure time-delay. This is done as a realistic approach to the problem to see how a simplified and more robust dynamic compensator will perform. If we had used a $4^{\text {th }}$ order element we could probably obtain a better compensation in the simulations. We think this is not particularly interesting in a simulation study (it would, however, be interesting to experiment with different dynamic elements on the real process).

The dynamic feed forward compensator seemed to give the best performance when the time constant equalled twice the residence time corresponding to the theoretical time constant from the input (feed) to where the nickel carbonate enters the reactor, or the pure time delay equalled $85 \%$ of this time constant. As mentioned above should the dynamic compensation ideally consist of four first order transfer functions, where the sum of the four time constants equals this residence time. The two different dynamic feed forward compensators showed almost the same performance. The performance of the feed forward compensators and the pure PID controller are shown in Fig. 7. The static gain compensator reduces the performance of the control system, because it does not take into consideration that there are inherent dynamics in flow (dispersion) from the input of the reactor to where the nickel carbonate enters the reactor. The dynamic feed forward compensator does improve the performance, and reduces the magnitude of the deviations to close to $0 \cdot 1 \mathrm{pH}$ units.

\section{Conclusions}

The main conclusion from this work is that it for the process in question is sufficient to use a standard PID controller for $\mathrm{pH}$ control. A dynamic feed forward compensator may further increase the performance. The precipitation process is approximately linear in $\mathrm{pH}$ in the actual operational area, and the resulting controller bandwidth is only a function of the residence time and the dispersion in the reactor. 


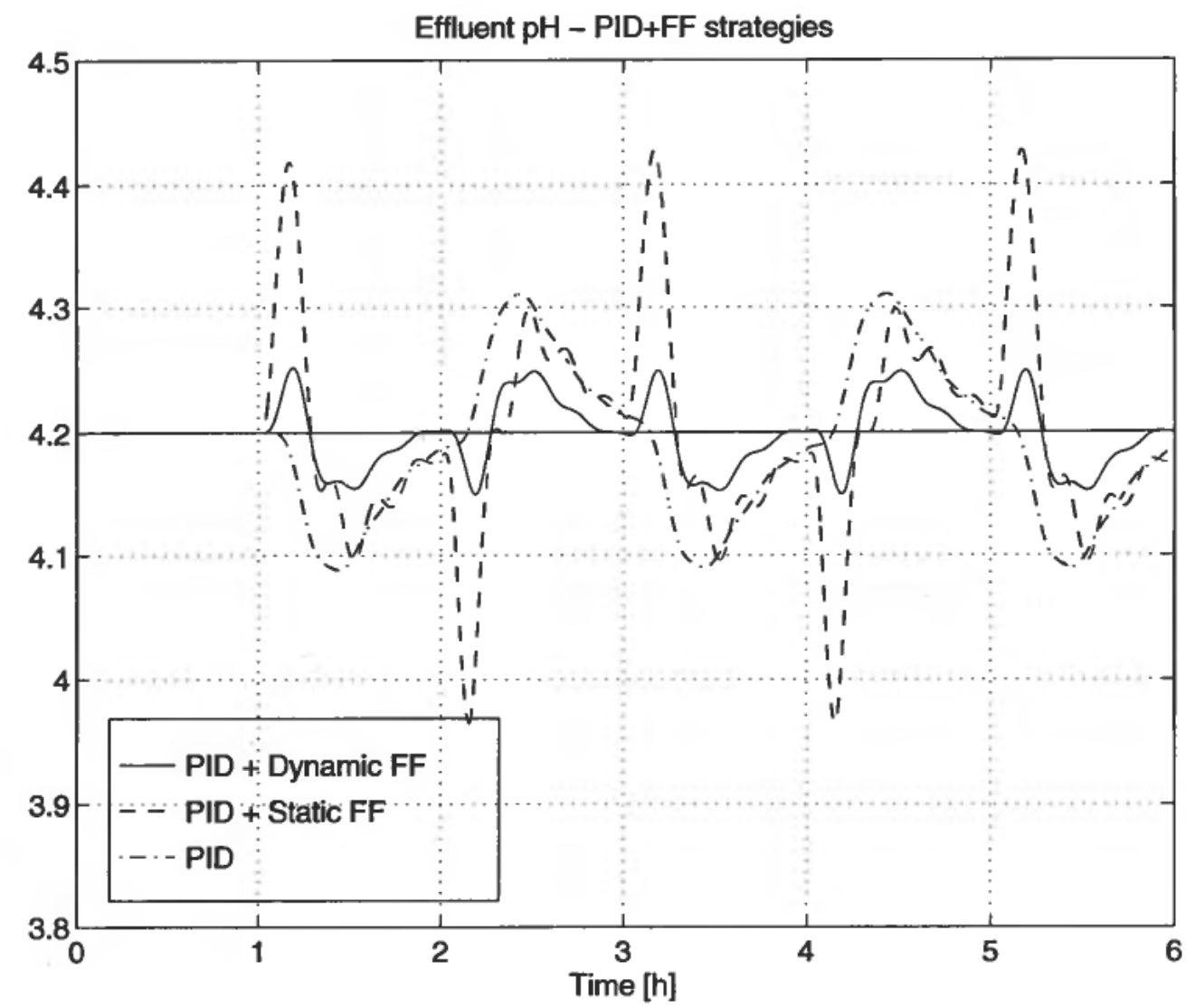

Figure 7. Feed forward and PID controller performance.

\section{ACKNOWLEDGEMENTS}

This work was financially supported by the Research Council of Norway, the Norwegian Federation of Process and Manufacturing Industries, and Falconbridge Nikkelverk in Norway.

\section{REFERENCES}

ASBJøRNSEN, O. A. (1972). Reaction invariants in the control of continuous chemical reactions. Chem. Eng. Sci., 27, 709-717.

FNA, (1994-97). Private communication with personnel at Falconbridge Nikkelverk A/S during the period 1994-1997.

Gustafsson, T. K., SkifVARS, B. O., SAndström, K. V. and Waller, K. V. (1995). Modelling of $\mathrm{pH}$ for Control. Ind. Eng. Chem. Res., 34, 820-827.

GustafSSON, T. K. and WALleR, K. V. (1992). Nonlinear and Adaptive Control of pH. Ind. Eng. Chem. Res., 31, 2681-2693.

Herskovitch, H. Z., MCAvoy, T. J. and Athansios, I. L. (1978). Can. Journal of Chem Eng., 56.

Holcroft, G., Rosato, L., Perrier, M. and Berk, D. (1995). Dynamics of the Jarosite Conversion Process. Preprints from DYCORD + '95, Helsing $\phi r$, Denmark.

McAvoy, T. J., Hsu, E. and LowENTHAL, S. (1972). Dynamics of pH in a Controlled Stirred Tank Reactor. Ind. Eng. Chem. Proc. Dev., 11, 68-70.

NeWEll, R. B. and LeE, P. L. (1988). Applied process control - a case study. Prentice Hall. Rosseland, E. W. (1993). Operational manual for the electrolyte purification section. Falconbridge Nikkelverk, Kristiansand (in Norwegian). 
SANDSTRÖM, K. V. and GuSTAFSSON, T. K. (1994). A study of the dynamics of calcium-phosphate precipitation in pH-control systems. Report 94-5, Åbo Akademi, Process Control Laboratory.

SLOTINE, J.-J. E. and LI, W. (1991). Applied Nonlinear Control. Prentice-Hall International, Inc. Støle-Hansen, K. and DotTerud, O. M. (1996). Dynamic Modelling of a Precipitation Process in an Aqueous Solution. Computers chem. Engng., 20, Suppl., S629-634.

TraA, S. (1994). Precipitation of Lead from Nickel Chloride Solutions. M.Sc. thesis (in Norwegian). Dep. of Chemical Engineering, the Norwegian Institute of Technology.

WALLER, K. V. and GuSTAFSSON, T. K. (1986). Fundamental Properties of Continous pH Control. ISA Trans., 22, No. 1, 12-34.

WALLER, K. V. and MÄKILÄ, P. M. (1981). Chemical Reaction Invariants and Variants and Their Use in Reactor Modelling, Stimulation and Control.

Wright, R. A. and KRAVARIS, C. (1995). pH Control in the Presence of Precipitation Equilibria. Preprints from DYCORD + '95, Helsing $\phi$, Denmark.

\section{Appendix A}

\section{A Dynamic Model of the Precipitation Reactor}

\section{(Støle-Hansen and Dotterud 1996)}

The nonlinear plug flow like reactor (PFR) is modelled as a 'tanks-in-series' model (see Fig. A.1). A residence time distribution (RTD) test (Traa 1994) gave an estimate of the axial dispersion in the PFR corresponding to 7.9 elements in a tanks-in-series model (total residence time $\sim 1500 \mathrm{~s}$ ). Based on those findings we used eight equal sized continuous stirred tank reactor (CSTR)-elements in our model. The nickel carbonate is introduced some distance down in the reactor corresponding to element number five (see Fig. 2).

The choice of state variables in the model is based on the theory of reaction invariants and variants (Asbjørnsen 1972), (McAvoy et al. 1972), Waller and Mäkilä 1981). We assume that the reactions (1)-(3) have finite reaction rates, and that the reactions (4)-(6) are 'instantaneous', and selected the 'total concentrations', e.g.

$$
W_{I}=C_{\mathrm{Ni}^{2}}+\mathrm{C}_{\mathrm{Ni}(\mathrm{OH})_{3}}+\mathrm{C}_{\mathrm{NiCO}}
$$

and the charge balance as reaction invariants.

In addition we choose the concentration of nickel carbonate $\left(\mathrm{C}_{\mathrm{NiCO}_{3}}\right)$ and the precipitates $\left(\mathrm{C}_{\mathrm{Ni}(\mathrm{OH})_{3}}\right.$ and $\left.\mathrm{C}_{\mathrm{PbO}_{2}}\right)$ as reaction variants. The three reactions having infinite rates (equations (4)-(6)) gives three algebraic equations represented with the respective equilibrium expressions (carbon acid protolysis and water protolysis). Each of the ideal

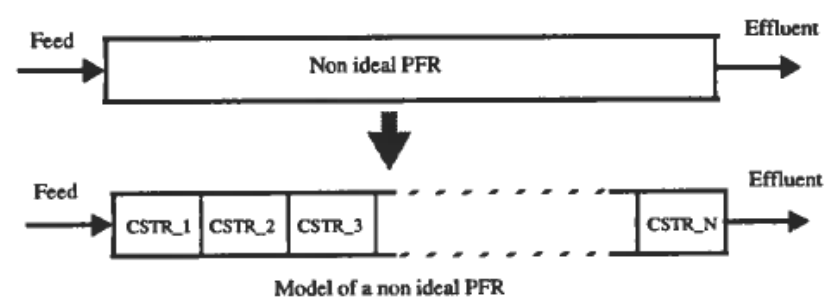

Figure A.1. 'Tanks-in-series' model of an non-ideal plug flow reactor. 


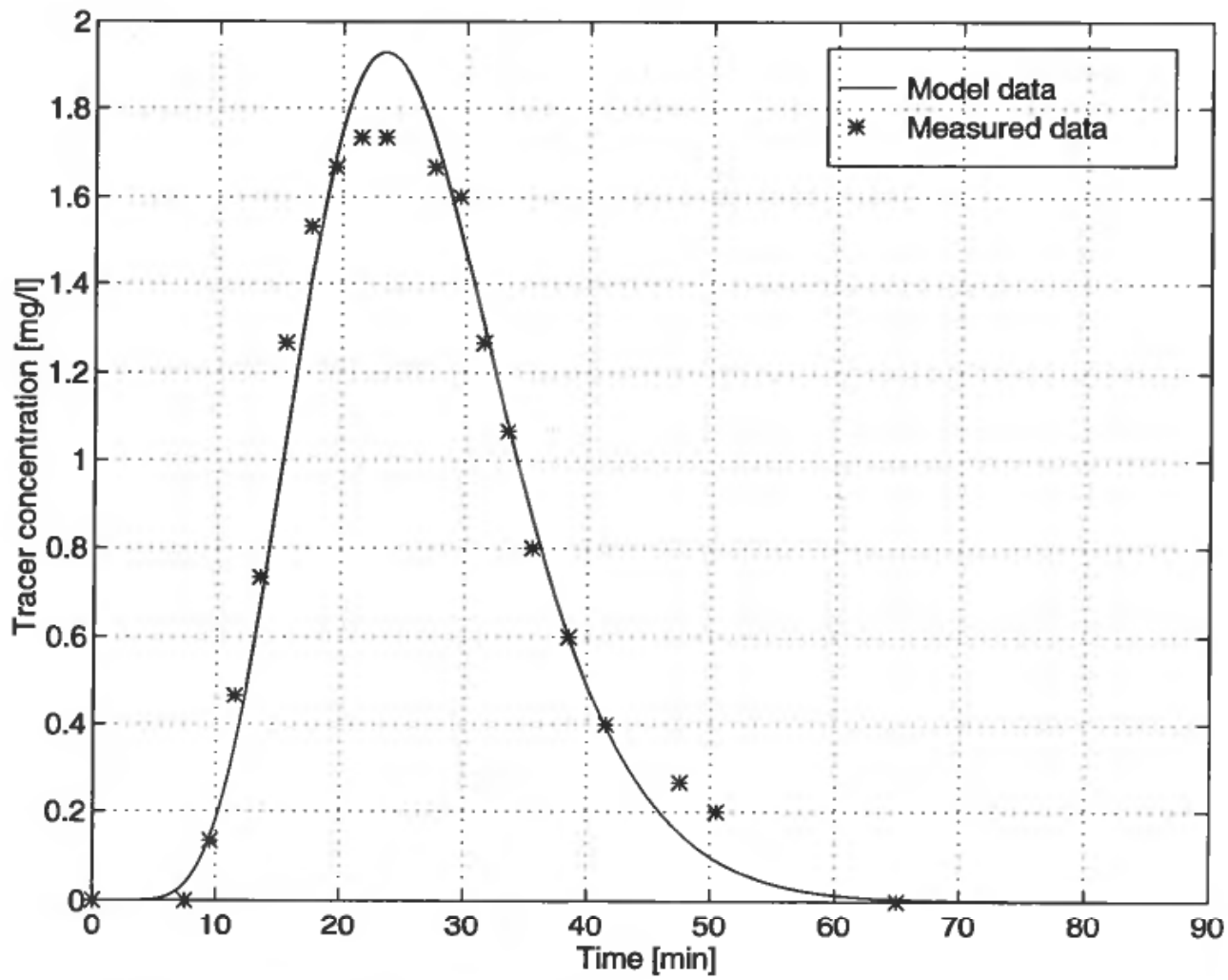

Figure A.2. Simulated and measured 'C-curve' in a residence distribution test.

CSTR-elements then consists of ten state variables with corresponding differential equations, which for an ideal continuous stirred tank reactor gives:

$$
\frac{d w}{d t}=-\frac{1}{\tau_{e}} w+\frac{1}{V} \sum F_{f} w_{f}
$$

and

$$
\frac{d x}{d t}=-\frac{1}{\tau_{e}} x+\frac{1}{V} \sum F_{f} x_{f}+N r,
$$

where $V$ is the volume of the reactor, $F$ is the flow rates (feed, effluent), $w / x$ is the reaction invariant/variant vector, $r$ is the reaction rate vector, $N$ is a stoichiometric matrix and $\tau_{e}=\frac{V}{\sum F_{e}}$.

The approximated expressions for the precipitation and dissolution rates was selected as:

$$
\begin{aligned}
r_{\text {niCO3 }} & =k O_{\mathrm{NiCO} 3}\left(\left[\mathrm{NiCO}_{3}\right]\left[\mathrm{H}^{+}\right]-\left(I / K_{\mathrm{NiCO}}\right)\left[\mathrm{N}_{\mathrm{i}}^{2+}\right]\left[\mathrm{HCO}_{3}-\right]\right) \\
r_{n i(\mathrm{OH}) 3} & =k O_{\mathrm{Ni}(\mathrm{OH}) 3}\left(\left[\mathrm{~N}_{\mathrm{i}}^{2+}\right]\left[\mathrm{OH}^{-}\right]\left[\mathrm{Cl}_{2}\right]-\left(1 / K_{\mathrm{Ni}(\mathrm{OH}) 3}\right)\left[\mathrm{Ni}(\mathrm{OH})_{3}\right]\left[\mathrm{Cl}^{-}\right]\right) \\
r_{\mathrm{PbO} 2} & =k O_{\mathrm{PbO}_{2}}\left(\left[\mathrm{~Pb}^{2+}\right]\left[\mathrm{OH}^{-}\right]\left[\mathrm{Cl}_{2}\right]-\left(1 / K_{\mathrm{PbO}_{2}}\right)\left[\mathrm{PbO}_{2}\right]\left[\mathrm{Cl}^{-}\right]\right)
\end{aligned}
$$

where $\mathrm{kO}_{\mathrm{NiCO}}$ is a reaction rate constant, and $\mathrm{K}_{\mathrm{NiCO}}$ is an equilibrium constant. 


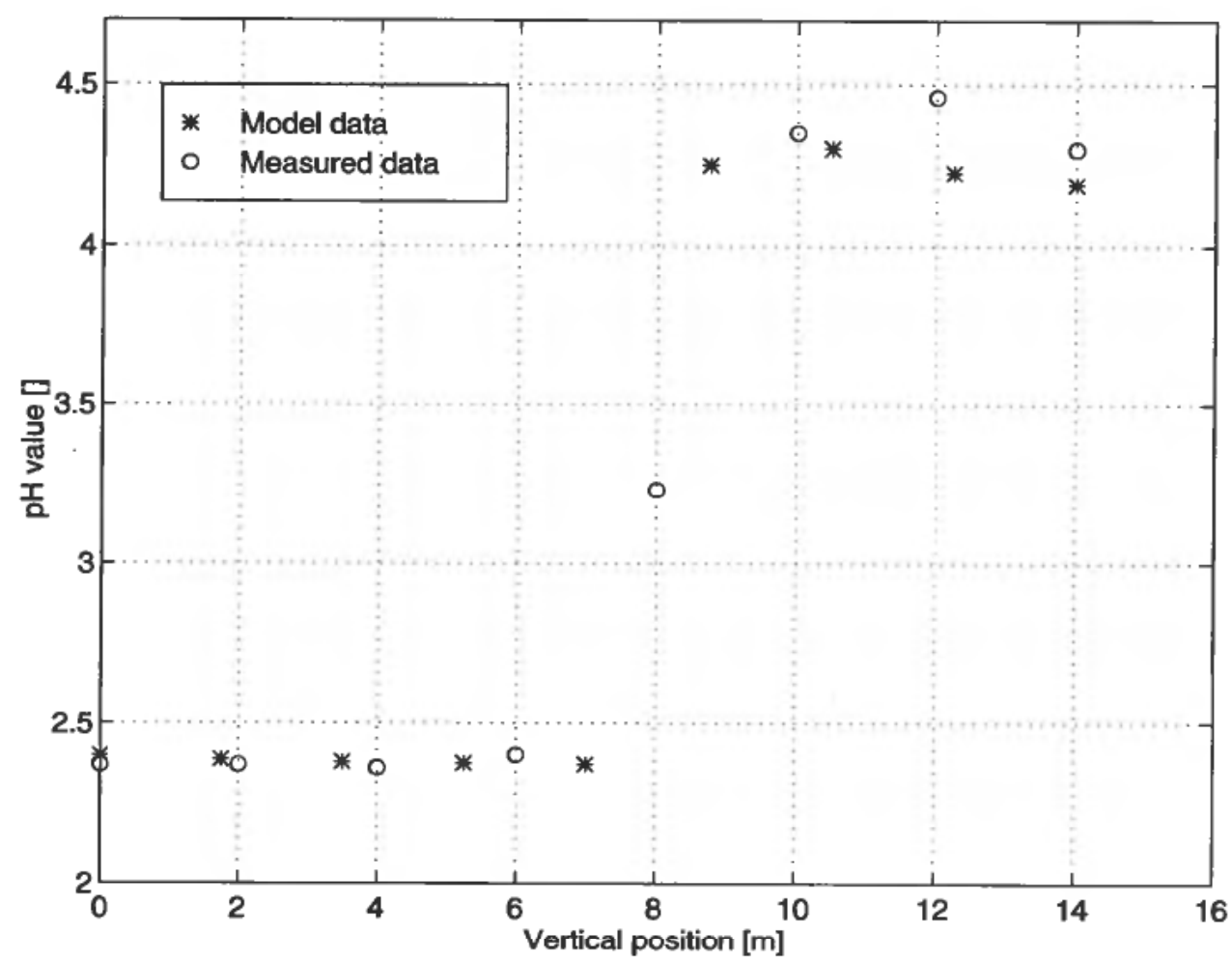

Figure A.3. Simulated and measured steady state vertical profile of $\mathrm{pH}$.

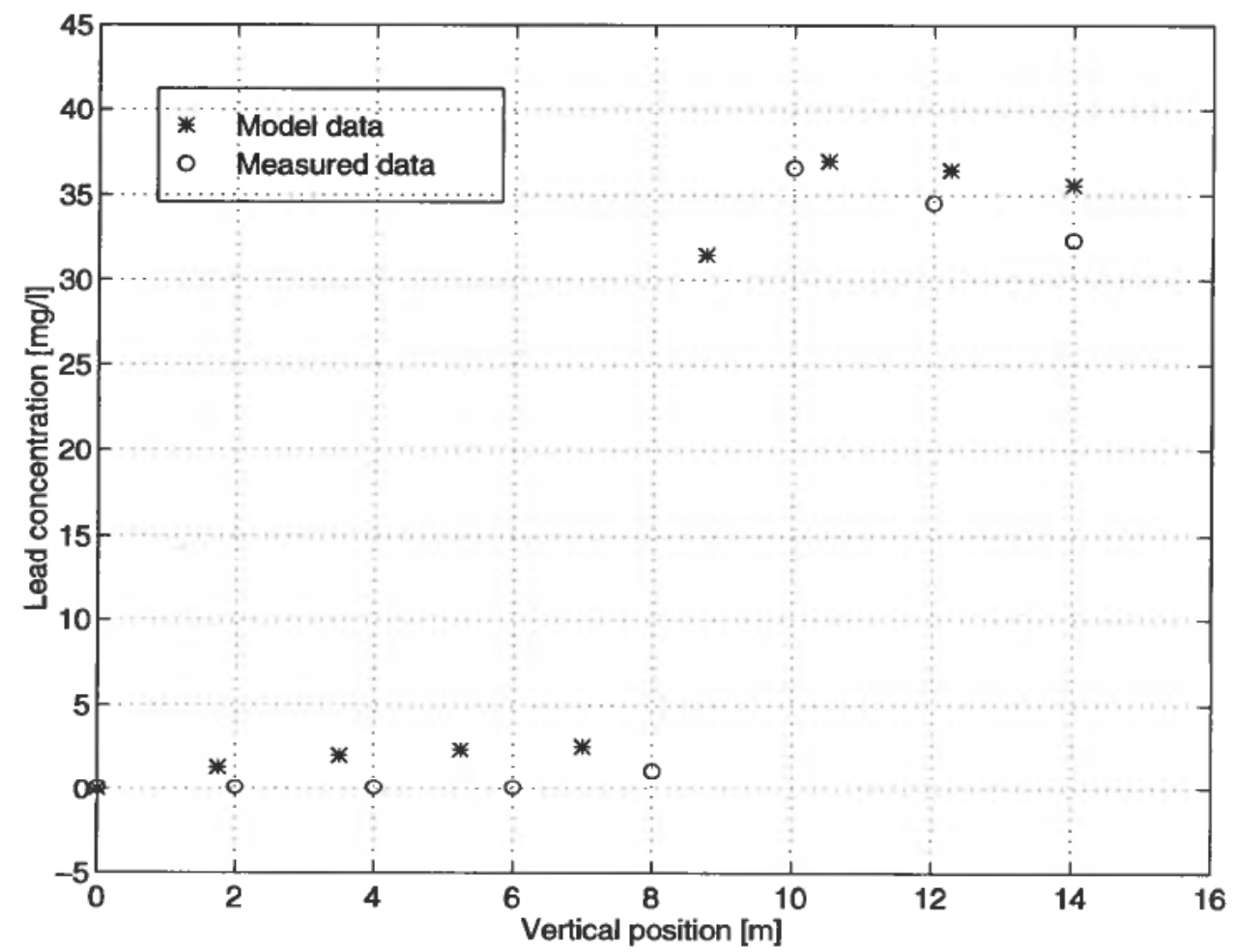

Figure A.4. Simulated and measured steady state vertical profile of precipitated lead. 


\section{Validation of the model}

The model was validated against experimental and operational data. In Fig. A.2 we have plotted the simulated and measured data from a residence distribution test, and Fig. A.3 and Fig. A.4 show the steady state vertical reactor profiles of $\mathrm{pH}$ and precipitated lead (which is the most important impurity). Fig. A.5 shows a ballistic simulation of the $\mathrm{pH}$ value in the effluent stream, where the measured input of nickel carbonate and chlorine gas is given as input to the model and the measured and the resulting simulated $\mathrm{pH}$ value is plotted in the same axis. The figures show that the model, including the calculation of the $\mathrm{pH}$ values and the formation of precipitates, primarily responds correct to the input of chlorine and carbonate.

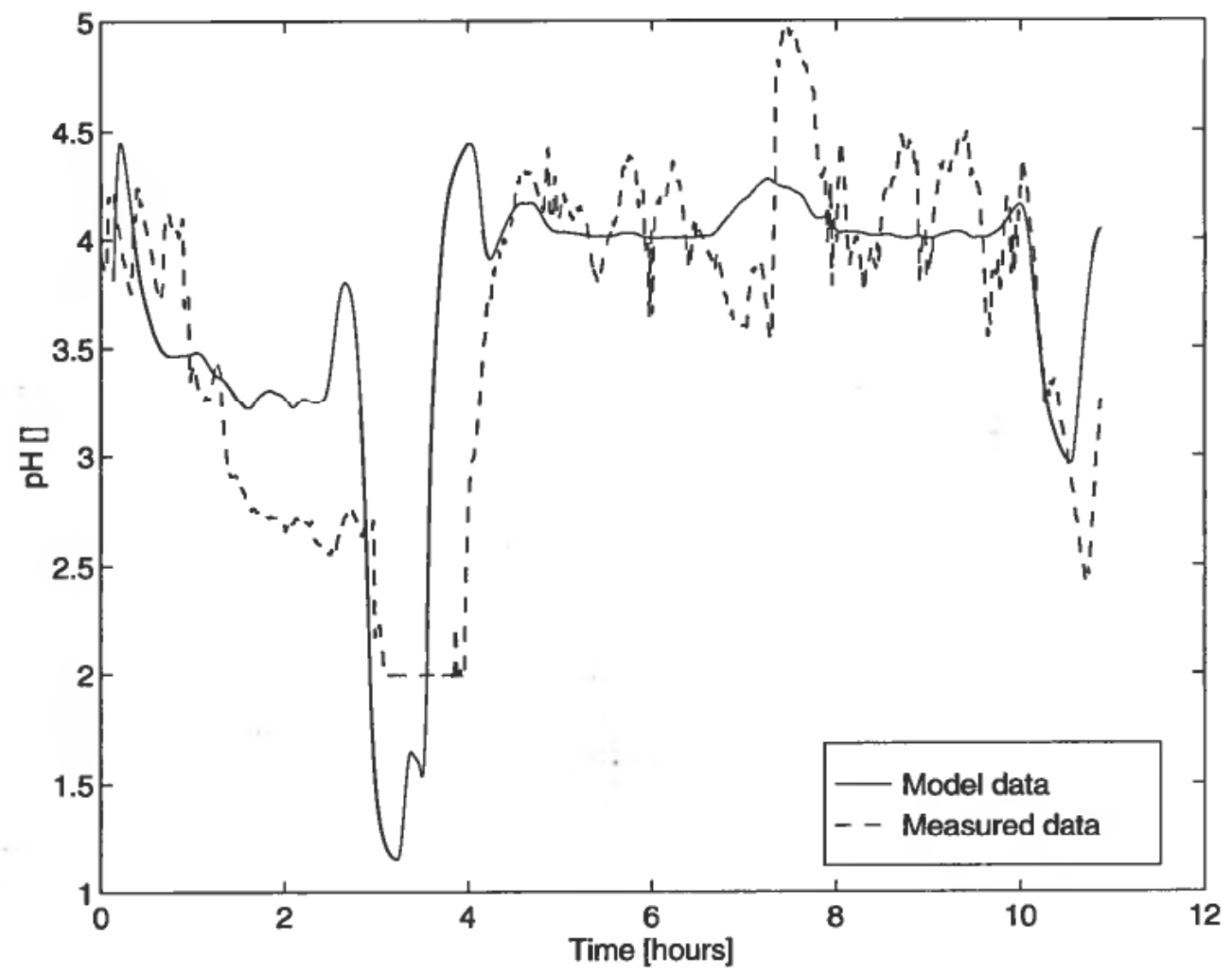

Figure A.5. A ballistic simulation of the effluent $\mathrm{pH}$ value. 